\title{
Article
}

\section{Do the same risk and protective factors influence aggression towards partners and same-sex others?}

Bates, EA, Archer, John and Graham-Kevan, Nicola

Available at http://clok.uclan.ac.uk/15329/

Bates, EA, Archer, John ORCID: 0000-0003-0483-1576 and Graham-Kevan, Nicola ORCID: 0000-0003-0621-3093 (2017) Do the same risk and protective factors influence aggression towards partners and same-sex others?

Aggressive Behavior, 43 (2). pp. 163-175. ISSN 0096-140X

It is advisable to refer to the publisher's version if you intend to cite from the work. http://dx.doi.org/10.1002/ab.21672

For more information about UCLan's research in this area go to http://www.uclan.ac.uk/researchgroups/ and search for <name of research Group>.

For information about Research generally at UCLan please go to http://www.uclan.ac.uk/research/

All outputs in CLoK are protected by Intellectual Property Rights law, including Copyright law. Copyright, IPR and Moral Rights for the works on this site are retained by the individual authors and/or other copyright owners. Terms and conditions for use of this material are defined in the policies page.

\section{CLoK}

Central Lancashire online Knowledge www.clok.uclan.ac.uk

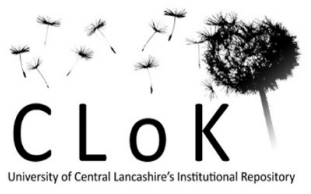


Running Head: RISK AND PROTECTIVE FACTORS OF AGGRESSION

Do the same risk and protective factors influence aggression towards partners and same-sex others?

\author{
Elizabeth A. Bates* \\ University of Cumbria,
}

John Archer and

Nicola Graham-Kevan,

University of Central Lancashire

Author Note

Correspondence should be addressed to Dr Elizabeth A. Bates, University of Cumbria, Fusehill Street Campus, Carlisle, CA12HH, UK

(Elizabeth.Bates@cumbria.ac.uk) 
RISK AND PROTECTIVE FACTORS OF AGGRESSION

\begin{abstract}
The current studies examined whether several risk and protective factors operate similarly for Intimate Partner Violence (IPV) and same-sex aggression (SSA) in the same sample, and to assess whether they show similar associations for men and women. Study $1(N=345)$ tested perceived benefits and costs, and instrumental and expressive beliefs about aggression: perceived costs predicted IPV and SSA for both men and women. Expressive beliefs predicted IPV (more strongly for women), and instrumental beliefs predicted SSA. Study 2 $(N=395)$ investigated self-control, anxiety and empathy, finding that self-control strongly predictor both types of aggression in both sexes. Study $3(N=364)$ found that primary psychopathy (involving lack of anxiety) was associated with IPV for men and SSA in both sexes, whereas secondary psychopathy (involving lack of self-control) was associated with IPV and SSA in both sexes. Overall there were both similarities and differences in the risk factors associated with IPV and SSA, and for men and women. The implications of the findings for theoretical debates about the study of IPV are discussed.
\end{abstract}

Key Words: intimate partner violence; aggression; self-regulation; self-control; risk factors 
RISK AND PROTECTIVE FACTORS OF AGGRESSION

Intimate Partner Violence (IPV) has typically been studied separately from aggression towards non-partners, and there are contrasting patterns for sex differences in physical aggression to same-sex and opposite-sex opponents: men showed considerably higher values than women for same sex-aggression, whereas for aggression to the opposite sex, there was a small difference in the female direction (Archer, 2004). These findings broadly parallel the contrast between IPV ${ }^{1}$, where there is little or no sex difference when behavioral measures are used (Archer, 2000; 2002) and physical aggression when no target is specified, where there is a large sex difference in the male direction (Archer, 2004.

These summaries are based on meta-analyses. A number of individual studies have investigated the contrasting pattern of sex differences in the same sample. Cross and Campbell (2012) found that men were more likely to report being aggressive to other men who were known to them than to partner; women, in contrast, were more likely to report being aggressive to partners than to other women who were known to them. The same pattern was found by Bates, Graham-Kevan, and Archer (2014) who also examined controlling behavior, which is an important predictor of IPV (e.g. Archer, 2013, Table 11; GrahamKevan \& Archer, 2005; 2008; 2009). Women showed more frequent controlling behavior to their partners than men did, and this behavior was associated with both IPV and SSA.

The present study extends these studies to assess whether IPV and SSA are associated with similar risk and protective factors, and whether these are similar in the two sexes. From the perspective of general theories of aggression and violence (e.g., Anderson \& Bushman, 2002; Berkowitz, 1993, pp. 240-271; Felson, 2002), we might expect IPV to operate according to a set of principles that apply to all forms of aggression, and to both sexes. These principles would include similar risk and protective factors. Nevertheless, within these general frameworks, there is scope for expecting contextual and sex differences. Indeed,

\footnotetext{
${ }^{1}$ Whilst there is a growing body of literature on same-sex relationships, this paper and study concentrates on opposite-sex relationships and the male/female dynamic throughout
} 


\section{RISK AND PROTECTIVE FACTORS OF AGGRESSION}

Felson (2002), who has advocated studying IPV within the context of violence and aggression in general, nevertheless emphasized protective factors that apply only to male IPV, and risk factors that apply only to women's IPV. In this context, we should note that risk and protective factors are often the same concept scored inversely: for example impulsiveness and self-control.

We report three studies (involving three samples previously collated and analyzed by Bates et al., 2014), to examine several possible risk and protective factors. We chose variables that were associated with higher or lower levels of aggression in previous studies: (1) stated costs and benefits of aggressive acts (Archer \& Southall, 2009; Archer, FernándezFuertes, \& Thanzami, 2010; Rutter \& Hine, 2005), (2) instrumental and expressive beliefs about aggression (Archer \& Haigh, 1997a; Archer \& Graham-Kevan, 2003; Campbell, Muncer \& Gorman., 1992), (3) self-control (Stanford, Houston, Villemarette-Pitman, \& Greve, 2003), (4) empathy (e.g. Jolliffe \& Farrington, 2004), (5) anxiety (e.g., Taft et al., 2006) and (5) psychopathic traits (e.g., Reidy, Zeichner \& Martinez, 2008). From general theories of aggression, we might expect these risk or protective factors to operate in both sexes and for both contexts of aggression. However, the studies reviewed above did suggest the possibility that some protective influences might be greater for men's than women's IPV and greater for women's than men's same-sex aggression.

\section{Research Overview and Hypotheses}

We present three studies examining risk and protective factors known to affect aggression from a range of previous studies. We used these to assess whether their association with aggression was specific to the target (same-sex other or opposite-sex partner), or applied in both cases. Study 1 examined (1) the perceived costs and benefits of aggression, and (2) instrumental and expressive beliefs about aggression. Study 2 measured self-control, empathy, and anxiety, which have been found to be inversely associated with 
RISK AND PROTECTIVE FACTORS OF AGGRESSION

aggressive behavior. Study 3 examined self-reported primary psychopathy (associated with lack of empathy), and secondary psychopathy (associated with a lack of self-control).

\section{Samples and Procedure}

The three studies were advertised to undergraduate students as involving questionnaires intended for participants who were in a romantic relationship or had been in one of at least one month's duration. Participants who identified as being in a same-sex relationship were excluded due to their small numbers $(n=11)$. Table 1 shows the demographic data for each study.

The one measure common to all three studies was a modified version of the original Conflict Tactics Scales (CTS: Straus, 1979), used to assess IPV and SSA (described in Bates et al., 2014). The present study used only the physical aggression items from this scale. There were two versions: the first asked participants about their perpetration of IPV, the second asked about their perpetration of SSA, both during the past 12 months. The responses were recorded on a six-point scale based on the original CTS format: from 0 (this has never happened) to 6 (more than 20 times). The internal consistency was high for both IPV ( $\alpha$ $=.85)$ and $\operatorname{SSA}(\alpha=.92)$.

\section{Study 1}

We first investigated two pairs of variables that have been found act as risk and protective factors for both IPV and SSA: they are cost-benefit assessment of aggression, and beliefs about aggression.

Cost-benefit assessment. Some researchers place more emphasis on automatic processes as causes of aggression (e.g., Berkowitz, 1983, 1993, 2008) whereas others place more emphasis on controlled decision-making (e.g., Tedeschi \& Felson, 1994). Conscious assessment of costs and benefits is consistent with the latter view, often referred to as the "rational choice" approach (Piliavin, Gartner, Thornton, \& Matsueda., 1986). Here individuals are viewed as considering the costs and benefits of their aggression and the 


\section{RISK AND PROTECTIVE FACTORS OF AGGRESSION}

outcome of this evaluation is likely to influence their behavior. Benefits of aggression include "teaching someone a lesson" and "saving face", whereas costs include the threat of physical injury and fear of punishment (Archer et al., 2010; Archer \& Southall, 2009). Studies examining these alongside self-control (representing an automatic process) find that both predict aggressive behavior (Archer et al., 2010; Rutter \& Hine, 2005).

Beliefs about Aggression. Campbell and Muncer (1987) proposed there were sex differences in social representations of anger and aggression, later termed beliefs about aggression (Archer \& Haigh, 1997a). The beliefs were characterized as men tending to view their aggression in an "instrumental" way, as a justification for their actions, and women tending to view it in a more "expressive" way, as an excuse for loss of control (Astin, Redston, \& Campbell, 2003). The EXPAGG was developed to assess these instrumental and expressive beliefs about aggression. Studies using this measure with the target of the aggression unspecified have found the predicted sex difference, women showing higher expressive beliefs and men showing higher instrumental beliefs (Archer \& Haigh, 1997a; Campbell, Muncer, \& Coyle, 1992; Campbell, Muncer, McManus, \& Woodhouse, 1999). Archer and Haigh (1999) examined the association between these beliefs and both SSA and IPV: in general, expressive beliefs were higher and instrumental beliefs lower for IPV than for SSA. Women were more expressive than men for both IPV and with SSA. Instrumental beliefs seemed to be more context-dependent, in that, men only showed higher instrumental beliefs than women when the target was the same sex, there being no significant difference for IPV. This probably reflected the generally negative attitudes towards male perpetration of IPV (Felson, 2002). In previous studies, the correlations between instrumental beliefs and general measures of aggression were positive and high whereas those for the expressive scale were negative and weak (Archer, 1997a, 1997b).

\section{Method}


RISK AND PROTECTIVE FACTORS OF AGGRESSION

Measures. Costs and benefits were measured by the Aggression Consequences Questionnaire (ACQ: Archer, et al., 2010). Participants completed two specific versions of this scale: in the first, they were asked to imagine that their partner had been annoying them and as a consequence they had hit him/her; and in the second they were to imagine the same for a same-sex other. Participants then rated 22 items that represented various costs and benefits associated with the aggressive act, and scored how much they endorsed each one. Participants scored how likely each cost/benefit would be on a scale of 5 (very likely) to 1 (very unlikely). The scale showed good reliabilities for IPV (costs: $\alpha=.83$; benefits: $\alpha=.89$ ) and SSA (costs: $\alpha=.88$; benefits: $\alpha=.95$ ).

Beliefs about aggression were measured using the shorter 16-item version of the EXPAGG (Campbell et al., 1999). Participants were asked to imagine that they had been in a physical fight with someone (target unspecified) and to then rate a list of statements about the use of their aggression. Responses were on a scale of 1 (strongly agree) to 5 (strongly disagree). Cronbach's $\alpha$ was .84 (instrumental) and .67 (expressive) $)^{2}$.

\section{Results}

Sex Differences. Since men were older than women in this sample, and studies show a decrease in physical aggression with age from young adulthood (e.g., Archer \& Haigh, 1997a; Eisner, 2002; Thanzami \& Archer, 2013), age was controlled in the analysis of sex differences. Table 2 shows the means and standard deviations for the sex differences analysis. There was no significant difference for physical aggression to partners, whereas men reported using significantly more physical SSA than women did. Men perceived significantly greater costs of IPV than women did but there was no significant difference for benefits. Men perceived significantly more benefits and fewer costs of SSA than women did. Men held

\footnotetext{
2 This scale has consistently been found to show a lower internal consistency than the instrumental scale (Campbell et al., 1999).
} 
RISK AND PROTECTIVE FACTORS OF AGGRESSION

significantly higher instrumental beliefs than women, and there was no sex difference in expressive beliefs, with little difference in the means (Table 2).

Correlation and Regression analyses. Table 2 shows the zero-order correlations between the two physical aggression measures, the cost-benefit scales, and the EXPAGG. IPV showed the expected positive correlation with perceived benefits of IPV, and the expected negative correlation with perceived costs of IPV, although the sizes are quite small. The same pattern was found for both sexes. SSA also showed the expected positive correlation with perceived benefits but the expected negative correlation with perceived costs was only significant for women. Instrumental beliefs were significantly positively associated with SSA (overall and for men and women), but they were only associated with IPV perpetration for women. Expressive beliefs showed little association with either IPV or SSA. There were also significant associations between the EXPAGG scores and the cost-benefit measures: instrumental beliefs showed strong correlations with both IPV benefits and SSA benefits, and weaker (negative) associations with perceived costs. Expressive beliefs showed weak associations with SS benefits for both sexes, and with IPV benefits for men but not women. Both costs and benefits showed significant positive correlations between the values for two types of opponent. The size of these associations was the same for men and women.

These variables were then regressed on IPV and SSA. In studies of physical aggression, the majority of participants are typically non-aggressive (Archer et al., 2010), thus creating a skewed data-set that is over-dispersed (standard deviation higher than the mean). This led to the choiceof Negative Binomial Regression for the analysis (Gardner, Mulvey, \& Shaw, 1995; Hilbe, 2007; Hutchinson \& Holtman, 2005).

Table 3 shows that perceived costs and expressive beliefs predicted IPV in the current sample. There was a significant interaction between sex and expressive beliefs indicating that the (positive) association between expressive beliefs and IPV was stronger in women 
RISK AND PROTECTIVE FACTORS OF AGGRESSION

than men. Perceived costs and instrumental beliefs were significant predictors of SSA; there were no interactions with sex, indicating this was to a similar extent in both men and women.

\section{Discussion}

In Study 1, we examined two pairs of risk and protective factors for IPV and SSA, in both men and women. The zer-order correlations showed consistency between IPV and SSA, in that men and women who perceived more benefits of IPV also saw more benefits of SSA, thus supporting the view that having a more aggressive personality is associated with more of both types of aggression. Similarly, those who perceived higher costs for one form of aggression also perceived higher costs for the other, suggesting that the same applies to assessment of the costs of aggression.

For SSA, perceived costs and instrumental beliefs were significant predictors when other variables were controlled, and this held for both sexes, despite men perceiving more benefits of SSA than women did. In numerous previous studies, instrumental beliefs and perceived benefits of aggression were positively associated with general measures of aggression (e.g., Archer \& Haigh 1997a; Campbell et al., 1992; Rutter \& Hines, 2005): in the present study, when other variables (including costs) were controlled, perceived benefits was not a significant predictor.

Viewing IPV as more costly was associated with lower IPV for both sexes. This occurred even though men perceived that IPV to be more costly than women did, which is consistent with previous findings (e.g., Cross \& Campbell, 2012) that men are more inhibited about physically aggressing to a female partner than to another man. There was no indication in the present study that costs were more closely associated with IPV in men than women., Expressive beliefs were a positive predictor of IPV in the present study, and this was more pronounced for women. The direction of the association is inconsistent with other studies showing a weak negative association with aggression in general (e.g., Archer \& Haigh, 
RISK AND PROTECTIVE FACTORS OF AGGRESSION

1997a, 1997b). Whereas the significant predictors of SSA were the same for both sexes for SSA, for IPV there was the one difference, that expressive beliefs were a stronger predictor for women than men.

The finding that instrumental beliefs were a significant predictor of SSA but not IPV is consistent with Archer and Haigh's (1999) finding that the association between instrumental beliefs and aggression appears to be more context-dependent than that for expressive beliefs, varying with the type of aggression and the opponent. However, in the present study, expressive beliefs were only a significant (negative) predictor of women's IPV, suggesting context-dependency here too, something that was not found for expressive beliefs in the previous study.

\section{Study 2}

Study 2 investigates three variables three that are, according to previous studies, negatively associated with aggression: self-control, empathy, and anxiety.

Self-Control. Many studies show an inverse association between self-control and aggression (e.g., Archer \& Southall, 2009; Archer \& Webb, 2006' Stanford, et al., 2003). Fewer studies have measured the association with IPV, although those that have (e.g., Field, Caetano, \& Nelson, 2004) also show a link with this type of aggression. The additive effect of high levels of self-control in members of a relationship dyad is also found to be an important predictor of relationship satisfaction (Vohs, Finkenauer, \& Baumeister, 2011). Together, these findings suggest that those with lower self-control are likely to show more of both IPV and SSA than those with high self-control. We therefore predicted that high selfcontrol would be negatively related to both types of aggression.

Empathy. Jolliffe and Farrington (2004) concluded that offending behavior by males was negatively related to empathy, with cognitive empathy being more strongly related than affective empathy. However, in a large sample of male and female adolescents who self- 


\section{RISK AND PROTECTIVE FACTORS OF AGGRESSION}

reported violent offending behavior in the classroom, only affective empathy was lower than in those who were not violent. Other studies show a negative association between empathy and IPV (e.g. Clements, Holtzworth-Munroe, Schweinle \& Ickes, 2007) and same-sex aggression (e.g. Miller \& Eisenberg, 1988) although a more recent meta-analysis found only a weak overall negative relationship between empathy and aggression, which varied little by type of aggression or empathy measure (Vachon, Lynam \& Johnson, 2014).

Anxiety. Typically, anxiety has been studied in relation to victimization, rather than perpetration (e.g., Kashani, Deuser \& Reid, 1991; Pico-Alfonso et al., 2006). In the current study, the association between anxiety and aggression perpetration was measured, to assess whether people higher in anxiety show less aggression than those who have lower levels.

\section{Method}

Measures. The aggression measures were those described earlier. Self-control was measured by the scale of Tangney, Baumeister, and Boone (2004), which asks participants to rate a list of 36 statements in terms of how well each describes them, from 1 (not at all) to 5 (very much). Cronbach's $\alpha=.85$ for the 36 items.

Empathy was assessed using the Interpersonal Reactivity Index (IRI: Davis, 1980), which asks participants to rate how much they agree with a number of statements about their thoughts and feelings, on a scale of 0 (doesn't describe me at all) to 4 (describes me perfectly). Cronbach's $\alpha=.82$ for the 28 items.

A new measure was developed for anxiety (the Dispositional Anxiety Measure, DAM; Bates, 2012; see Appendix 1 for full scale). It was created as a short scale to measure the general tendency to become anxious and worried. A review of existing anxiety measures showed that they were inappropriate for the current study: for example, the Beck Anxiety Inventory (BAI: Beck, Epstein, Brown \& Stear, 1988) and the Anxiety Sensitivity Index (ASI: Reiss, Peterson, Girsky \& McNally, 1986) both involved items about state rather than 
RISK AND PROTECTIVE FACTORS OF AGGRESSION

dispositional anxiety. The two most relevant measures were the Penn Worry Questionnaire (Meyer, Miller, Metzger \& Borkovec, 1990), which measures only the propensity to worry, and the Hamilton Anxiety Scale (Hamilton, 1959) which is an interview rather than selfreport measure. The items on the DAM were scored on a five-point scale from 0 (doesn't describe me at all) to 4 (describes me perfectly). Cronbach's $\alpha=.85$ for the 10 items.

\section{Results}

Sex-differences. Table 4 shows that, controlling for age, the sexes showed no difference in physical aggression to a partner. Men perpetrated significantly more same-sex physical aggression than women. There was no significant sex difference in self-control; women reported higher levels of empathy and anxiety than men did.

Correlation and Regression analysis. Self-control was significantly negatively, but weakly, correlated with both IPV and SSA, and this was the case for both sexes (Table 4). Anxiety was significantly (but weakly) correlated with IPV overall but not for the two sexes separately; it was also significantly correlated with SSA for men but not for women. Empathy showed no significant correlations with either type of aggression. Anxiety was significantly positively correlated with empathy and negatively correlated with self-control. The magnitude of these associations was similar for men and women.

Anxiety, empathy and self-control were regressed onto IPV perpetration and then to SSA. Table 5 shows the results of the regressions. Self-control was the only significant predictor for both IPV and SSA with no significant interactions with sex, indicating consistency for men and women.

\section{Discussion}

In Study 2, we examined whether the three variables were negatively associated with the two forms of aggression (IPV and same-sex aggression) and whether there were-sex specific and target-specific effects. Only self-control was significantly negatively associated 


\section{RISK AND PROTECTIVE FACTORS OF AGGRESSION}

with both forms of aggression in both sexes. This finding is consistent with the view (e.g. Felson \& Lane, 2010) that IPV has a substantially similar etiology to other forms of violence, and it broadly supports previous findings that similar personality factors are related to IPV perpetration as to other violent acts (e.g., Ehrensaft, Cohen, \& Johnson, 2006; Moffitt, Caspi, Rutter, \& Silva, 2001). It also supports the approach of studies that have included measures of both types of aggression within the same sample of men and women (e.g., Archer \& Webb, 2006; Bates et al, 2014; Cross \& Campbell, 2012).

The finding that self-control was the only significant statistical predictor of aggression may mean that this variable underlies other protective factors, which work through, or are mediated by it, although in the present sample, only anxiety and IPV were associated at a bivariate level, and then only weakly. The lack of significant associations between aggression and empathy is inconsistent with some previous findings mentioned in the introduction and also that of Kaukiainen et al. (1999), although as mentioned a recent meta-analysis that overall the relationship is weak (Vachon et al., 2014).

\section{Study 3}

Psychopathy involves a superficial, charming and unreliable manner, with an absence of delusion and nervousness or neurosis (Cleckley, 1976). Psychopaths have a pathological egocentric nature and a general incapacity to love, including a poverty of affective emotions. Many studies have developed and examined the underlying factors within the psychopathic personality (e.g., Karpman, 1941; Cleckley, 1976). The two-factor model of psychopathy distinguishes primary and secondary psychopathic traits, which are associated with a lack of anxiety and a lack of self-control respectively. Primary and secondary psychopaths are similar in their manifestation of antisocial behavior and deceit, but it is likely that primary psychopathy involves an affective deficit, whereas secondary psychopathy involves an affective disturbance, with underlying anxiety, depression and neuroses. 
RISK AND PROTECTIVE FACTORS OF AGGRESSION

Psychopathis traits have been associated with higher levels of both general aggression and IPV (e.g. Meloy, 1997; Grann \& Wedin, 2002; Reidy, Zeichner, \& Martinez, 2008), leading to the prediction that higher levels of both primary and secondary psychopathic traits will be associated with higher levels of IPV and SSA in the present student sample.

\section{Method}

Measures. Participants' psychopathic traits were measured by the Levenson SelfReport Psychopathy Scale (LSRP: Levenson, Kiehl, \& Fitzpatrick, 1995), which consists of two subscales, Primary and Secondary ( $\alpha=.86$ and .71 respectively).

\section{Results}

Sex Differences. Table 6 shows that, controlling for age, women were significantly more physically aggressive to their partners than were men, and that men were more physically aggressive to same-sex others. Men had significantly higher primary psychopathic trait scores than women; there was no significant sex difference for secondary psychopathy.

Correlation and Regression analyses. There were the predicted positive correlations between both forms of aggression and psychopathic traits, overall, and for both men and women (Table 7). The association between IPV and primary psychopathy was higher for male than female participants although this was non-significant $(\mathrm{Z}=1.41, p$ $=.150$ : Preacher, 2002) and the association between SSA and primary psychopathy was significant for female but not for male participants. These correlations were all positive but small in size magnitude.

The regression for IPV perpetration indicated that secondary psychopathy was a significant predictor but primary psychopathy was not (Table 10). The significant interaction between sex and primary psychopathy indicated that this was a stronger predictor for men than women. For SSA, both primary and secondary psychopathy were significant predictors, and there was no significant interaction with sex, indicating consistency in both sexes. 
RISK AND PROTECTIVE FACTORS OF AGGRESSION

\section{Discussion}

This study further explored the anxiety and self-control, in the form of primary and secondary psychopathy. We found, as predicted, that psychopathy statistically predicted both IPV and SSA: primary psychopathy was a significant predictor of SSA but only predicted IPV for men, whereas secondary psychopathy predicted both IPV and SSA for both sexes..

The general finding that psychopathy is associated with aggression is consistent with many previous studies involving general aggression (e.g., Meloy, 1997; Reidy et al., 2008) and IPV (e.g., Coyne, Nelson, Graham-Kevan, Kesiter \& Grant, 2010; Huss \& Langhinrichsen-Rohling, 2000; Grann \& Wedin, 2002). However, other studies suggest that the link between psychopathy and aggression is more complex. In a meta-analysis, Lorber (2004) examined the association between aggression, psychopathy and conduct problems alongside two physiological measures (heart rate and electrodermal activity) that are often seen as behavioral markers. There were underlying physiological differences between conduct disorder, psychopathy and aggression which pointed to a degree of behavioral specificity in these aspects of autonomic functioning. This indicated that the assumed, and often discussed, relationship between psychopathy and aggression may be subject to mediating effects. Lorber pointed to heterogeneity among studies and the general focus in the field of examining the main effects, neglecting important interactions.

Men scored significantly higher than women on the primary scale, whereas there was no significant sex difference for the secondary psychopathy scale. Primary psychopathy is regarded as being linked to an underactive BIS system, which is characterized by regulating behavior such as anxiety, higher levels of which are usually found for women than men (e.g., Feingold, 1994; Kessler et al., 1994; Lewinsohn, Gotlib, Lewinsohn, Seeley, \& Allen, 1998). This could go some way to explaining why men are more likely to endorse primary psychopathic traits, which involve a lack of anxiety. Secondary psychopathy is more 
RISK AND PROTECTIVE FACTORS OF AGGRESSION

associated with impulsivity, aspects of which (e.g., risk taking, risky impulsivity, sensation seeking, and reward sensitivity) are found to be higher in men than women (e.g., Cross, 2010; Cross, Copping \& Campbell, 2011; Cross, Cyrenne, \& Brown, 2013; Miettunen, Veijola, Lauronen, Kantojärvi, \& Joukamaa, 2007).

\section{General Discussion}

The aim of the studies presented here was to examine risk and protective factors for IPV and SSA within the same sample, and to assess possible sex-specific effects. The main findings were: (1) that IPV and same-sex aggression shared some of the same risk and protective factors, for example perceived costs of the aggressive act and self-control, although (2) there were some differences, for example instrumental beliefs and primary psychopathy predicted SSA but not IPV; (3) only one predictor was different for men and women, instrumental beliefs showing a stronger effect on women's than men's IPV.

Thus the current studies demonstrated considerable commonality in the predictors of IPV and SSA: perceived costs, self-control, and secondary psychopathy all predicted both; other variables - perceived benefits, empathy, anxiety - predicted neither. These findings support the view that IPV perpetration is best viewed as part of a generally aggressive and controlling interpersonal style (e.g., Corvo \& deLara, 2009), rather than having a separate aetiology solely in terms of men's coercive control (e.g. Dobash \& Dobash, 1979, 2004; Pence \& Paymar, 1993). This view is supported by other studies showing that IPV perpetration is associated with other forms of criminality (e.g. Felson \& Paré, 2005), youth violence (e.g., Herrenkohl et al., 2007), middle-school aggression (e.g., O’Donnell et al., 2006), general violence (e.g., Farrington et al., 2006), violent offending (e.g., Thornton, Graham-Kevan \& Archer, 2010), and bullying (e.g., Corvo \& DeLara, 2009). It is further supported by the longitudinal study of Moffitt et al. (2001), who found that the strongest risk factor for IPV perpetration, for both sexes, was a record of violent delinquent behavior. The 


\section{RISK AND PROTECTIVE FACTORS OF AGGRESSION}

present study supports such findings in that it showed similar risk factors for IPV and SSA, within the same sample. Foremost among these was self-control, In Study 2, which (in Study 2), was a consistent predictor of lower aggression, both for IPV and SSA, and for men and women, supporting many previous findings on dispositional self-control (e.g., Archer \& Southall, 2009; Stanford, et al., 2003; Tangney et al., 2004). Consistent with the finding for the direct measure of self-control, secondary psychopathy (related to low self-control) predicted both forms of aggression in Study 3.

There were also some differences in the predictors for the two types of aggression. Although, in Study 1, perceived costs predicted both forms of aggression, instrumental beliefs predicted SSA but not IPV, whereas expressive beliefs predicted IPV but not SSA. This suggests that SSA is more closely associated with a motive or justification in terms of controlling others, whereas IPV is more closely associated with a view that aggressive acts involve a loss of control (Astin et al., 2003; Campbell \& Muncer, 1987). In Study 3, primary psychopathy was a significant predictor for SSA but not for IPV: this form of psychopathy is related to low anxiety. We should be cautious in necessarily linking low anxiety with aggression, since the direct measure of anxiety used in Study 2 was unrelated to either form of aggression.

Of all the variables investigated in the three studies, only expressive beliefs demonstrated a significantly stronger association with aggression for one sex than the other, in this case for women's IPV. Driscoll, Zinkivskay, Evans and Campbell (2006) proposed that individuals with better inhibitory control, who are often women, express their anger when it is at a relatively higher level and emotional arousal is higher: thus, when they experience higher levels of provocation they are more expressive. Conflict with this type of provocation is more likely to occur within intimate relationships where opportunities for conflict and interdependence are higher (e.g. Finkel, 2007). 
RISK AND PROTECTIVE FACTORS OF AGGRESSION

Overall, the present findings support the view that IPV can be included in theories of aggression, such as the General Aggression Model (Anderson \& Bushman, 2002). Previous studies have shown the predictive power of these risk and protective factors acting separately: we have examined several of these together in relation to two forms of aggression for both men and women, within the same sample. The findings indicate more similarities than differences in the predictors of men's and women's aggression to both targets.

\section{Limitations and Future Research}

The present study has several limitations. It is correlational and cross-sectional in design. Many risk-factor studies share this design limitation and an improvement in this research area would be the addition of longitudinal studies that enable the causal direction of some of the variables to be studied. A further issue relates to the use of a Western, undergraduate student sample. Sex differences in aggression, specifically IPV vary across cultures that hold more traditional values. Cultures that have more gender equality in terms of societal power tend to have the most parity in IPV perpetration, and higher absolute rates perpetrated by women (Archer, 2006).

A second limitation involves the novel measure of anxiety that was created for the purpose of this project. Whilst showing good reliability, further psychometric analyses are needed to fully specify its utility. A further limitation concerns the interaction between the variables. In the current studies we examined associations, both in correlations and regressions: we did not investigate the possibility that some variables may act as mediators of the influence of others. By studying IPV and SSA within the same sample it presents the possibility of studying the interactions and meditational properties of different variables; it allows those that have been examined separately to be integrated and studied together. For example, we found the importance of self-control and psychopathic traits in predicting aggression, albeit in two separate studies. Secondary psychopathy is characterized by 
RISK AND PROTECTIVE FACTORS OF AGGRESSION

impulsivity, so that a study encompassing both psychopathy and self-control, including mediational analysis, may indicate which is the most important, or whether one is a symptom of the other. Alternatively, studying psychopathy and impulsivity would allow the relationship between psychopathy, reward sensitivity and punishment insensitivity, to be explored. Findings from such studies could then be incorporated into more effective interventions, particularly for IPV, where there is a need for more specific evidence-based interventions tailored to a more individual approach. This would contrast with currently-used approaches, such as the Duluth model (Pence \& Paymar, 1993), which assumes that patriarchal control is the sole motive for IPV.. 
RISK AND PROTECTIVE FACTORS OF AGGRESSION

\section{References}

Anderson, C.A., \& Bushman, B.J. (2002). Human aggression. Annual Review of Psychology, 53, 27-51. doi:10.1146/annurev.psych.53.100901.135231

Archer, J. (2000). Sex differences in aggression between heterosexual partners: A metaanalytic review. Psychological Bulletin, 126, 651-680. doi:10.1037/00332909.126.5.651

Archer, J. (2002). Sex differences in physically aggressive acts between heterosexual partners: A meta-analytic review. Aggression and Violent Behavior, 7, 313-351. doi:10.1016/S1359-1789(01)00061-1

Archer, J. (2004). Sex differences in real world settings: a meta-analytic review. Review of General Psychology, 8, 291-322. doi:10.1037/1089-2680.8.4.291

Archer, J. (2013). Can evolutionary principles explain patterns of family violence? Psychological Bulletin, 138, 403-440. doi: 10.1037/a0029114

Archer, J., Fernández-Fuertes, A.A., \& Thanzami, V.L. (2010). Does cost-benefit analysis or self-control predict involvement in two forms of aggression? Aggressive Behavior, 36, 292-304. doi:10.1002/ab.20358

Archer, J. \& Graham-Kevan, N.J.A. (2003). Do beliefs about aggression predict physical aggression to partners? Aggressive Behavior, 29, 41-54. doi:10.1002/ab.10029

Archer, J. \& Haigh, A. (1997a). Do beliefs about aggressive feelings and actions predict reported levels of aggression? British Journal of Social Psychology, 36, 83-105. doi:10.1111/j.2044-8309.1997.tb01120.x

Archer, J. \& Haigh, A. (1997b). Beliefs about aggression among male and female prisoners. Aggressive Behavior, 23, 405-415. doi: 10.1002/(SICI)10982337(1997)23:6<405::AID-AB1>3.0.CO;2-F 
RISK AND PROTECTIVE FACTORS OF AGGRESSION

Archer, J. \& Haigh, A. (1999). Sex differences in beliefs about aggression: Opponent's sex and the form of aggression. British Journal of Social Psychology, 38, 71-84. doi:10.1348/014466699164040

Archer, J. \& Southall, N. (2009). Does cost-benefit analysis of self-control predict involvement in bullying behavior by male prisoners? Aggressive Behavior. 35, 31-40. doi:10.1002/ab.20283

Archer, J. \& Webb, I. A. (2006). The relation between scores on the Buss-Perry Aggression Questionnaire and aggressive acts, impulsiveness, competitiveness, dominance and sexual jealousy. Aggressive Behavior, 32, 464-473. doi: 10.1002/ab.20146

Bates, E. A. (2012). The Relationship of Men's and Women's Partner Violence to Personality and Psychopathology. (Doctoral thesis). Retrieved from Central Lancashire Online Knowledge (http://clok.uclan.ac.uk/3146/)

Bates, E. A., Graham-Kevan, N. \& Archer, J. (2014). Testing predictions from the male control theory of men's partner violence. Aggressive Behavior, 40, 42-55. doi: 10.1002/ab.21499

Beck, A. T., Epstein, N., Brown, G \& Stear, R. A. (1988). An inventory for measuring clinical anxiety: Psychometric properties. Journal of Consulting and Clinical Psychology, 56, 893-897. doi: 10.1037/0022-006X.56.6.893

Berkowitz, L. (1983). Aversively stimulated aggression: Some parallels and differences in research with animals and humans. American Psychologist, 38, 1135-1144. doi: 10.1037/0003-066X.38.11.1135

Berkowitz, L. (1993). Aggression: Its causes, consequences, and control. New York: McGraw-Hill. 
RISK AND PROTECTIVE FACTORS OF AGGRESSION

Berkowitz, L. (2008). On the consideration of automatic as well as controlled psychological processes in aggression. Aggressive Behavior, 34, 117-129. http://dx.doi.org/10.1002/ab.20244

Campbell, A. \& Muncer, S. (1987). Models of anger and aggression in the social talk of women and men. Journal for the Theory of Social Behavior, 17, 489-511. doi: 10.1111/j.1468-5914.1987.tb00110.x

Campbell, A., Muncer, S. \& Coyle, E. (1992). Social representations of aggression as an explanation of gender differences: A preliminary study. Aggressive Behavior, 18, 95108. doi: 10.1002/1098-2337(1992)18:2<95::AID-AB2480180203>3.0.CO;2-5

Campbell, A., Muncer, S. \& Gorman, B. (1993). Sex and social representations of aggression: A communal-agentic analysis. Aggressive Behavior, 19, 125-136. doi: 10.1002/1098-2337(1993)19:2<125::AID-AB2480190205>3.0.CO;2-1

Campbell, A., Muncer, S., McManus, I. C. \& Woodhouse, D. (1999). Instrumental and expressive representations of aggression: one scale or two? Aggressive Behavior, 25, 435-444. doi: 10.1002/(SICI)1098-2337(1999)25:6<435::AID-AB4>3.0.CO;2-Q

Cleckley, H. (1976). The mask of sanity. St Louis MO: Mosley.

Clements, K., Holtzworth-Munroe, A., Schweinle, W. \& Ickes, W. (2007). Empathic accuracy of intimate partners in violent versus non-violent relationships. Personal Relationships, 14, 369-388. doi: 10.1111/j.1475-6811.2007.00161.x

Corvo, K. \& deLara (2009). Towards an integrated theory of relational violence: Is bullying a risk factor for domestic violence. Aggression and Violent Behavior, 15, 181-190. doi: 10.1016/j.avb.2009.12.001

Coyne, S. M., Nelson, D. A., Graham-Kevan, N., Keister, E., \& Grant, D. M. (2010). Mean on the screen: Psychopathy, relationship aggression, and aggression in the media. Personality and Individual Differences, 48, 288-293. doi:10.1016/j.paid.2009.10.018 
RISK AND PROTECTIVE FACTORS OF AGGRESSION

Cross, C.P. (2010). Sex differences in same-sex direct aggression and sociosexuality: The roles of risky impulsivity. Evolutionary Psychology, 8, 779-792.

Cross, C. P. \& Campbell, A. (2012). The effect of intimacy and target sex on direct aggression: Further evidence. Aggressive Behavior, 38, 272-280.

doi:10.1002/ab.21430

Cross, C. P., Copping, L. T. \& Campbell, A. (2011). Sex differences in impulsivity: A metaanalysis. Psychological Bulletin, 137, 97-130. doi: 10.1037/a0021591; 10.1037/a0021591.supp

Cross, C.P., Cyrenne, D.-L.M., \& Brown, G.R. (2013). Sex differences in sensation-seeking: A meta-analysis. Scientific Reports, 3, 2486. doi:10.1038/srep02486.

Davis, M. H. (1980). A multidimensional approach to individual differences in empathy. Catalogue of Selected Documents in Psychology, 10, 85. doi: 10.1037/00223514.44.1.113

Dobash, R.E., \& Dobash, R.P. (1979). Violence against wives: A case against the patriarchy. London: Open Books

Dobash, R. P. \& Dobash, R. E. (2004). Women's violence to men in intimate relationships: Working on a Puzzle. British Journal of Criminology, 44, 324-349. doi:10.1093/bjc/azh026

Driscoll, H., Zinkivskay, A., Evans, K. \& Campbell, A. (2006) Gender differences in social representations of aggression: The phenomenological experience of differences in inhibitory control? British Journal of Psychology, 97(2), 139-153. doi: $10.1348 / 000712605 \times 63073$

Ehrensaft, M. K., Cohen, P., \& Johnson, J. G. (2006). Development of personality disorder symptoms and the risk for partner violence. Journal of Abnormal Psychology, 115, 474 - 483. doi: 10.1037/0021-843X.115.3.474 
RISK AND PROTECTIVE FACTORS OF AGGRESSION

Eisner, M. (2003). Long-term historical trends in violent crime. Crime and Justice: A Review of Research, 30, 83-142.

Farrington, D. P., Coid, J.W., Harnett, L., Jolliffe, D., Soteriou, N., Turner, R. \& West, D.J. (2006). Criminal careers and life success: New findings from the Cambridge study in delinquent behavior. Home Office research study No. 281. London: Home Office.

Feingold, A. (1994) Gender differences in personality: a meta-analysis. Psychological Bulletin, 116, 429-456

Felson, R. B (2002). Violence and gender re-examined. American Psychological Association, Washington D. C.

Felson, R. B. \& Lane, K. J. (2010). Does violence involving women and intimate partners have a special etiology? Criminology, 48, 201-218. doi: 10.1111/j.17459125.2010.00186.x

Felson, R. B. \& Paré, P. (2005). The reporting of domestic violence and sexual assault by nonstrangers to the police. Journal of Marriage and Family, 67, 597-610. doi:10.1111/j.1741-3737.2005.00156.x

Field, C. A., Caetano, R., \& Nelson, S. (2004). Alcohol and violence related cognitive risk factors associated with the perpetration of intimate partner violence. Journal of Family violence, 19, 249-253. doi: 10.1023/B:JOFV.0000032635.42145.66

Finkel, E. J. (2007). Impelling and inhibiting forces in the perpetration of intimate partner violence. Review of General Psychology, 11, 193-207. doi: 10.1037/10892680.11.2.193

Gardner, W., Mulvey, E. P., \& Shaw, E. C. (1995). Regression analysis of counts and rates: Poisson, over-dispersed, and negative binomial models. Psychological Bulletin, 118, 392-404. doi:10.1037//0033-2909.118.3.392 
RISK AND PROTECTIVE FACTORS OF AGGRESSION

Grann, M. \& Wedin, I. (2002). Risk factors for recidivism among spousal assault and spousal homicide offenders. Psychology, Crime \& Law, 8, 5-23. doi:

$10.1080 / 10683160208401806$

Graham-Kevan, N. \& Archer, J (2005) Investigating three explanations of women's relationship aggression. Psychology of Women Quarterly, 29, 270-277. doi:10.1111/j.1471-6402.2005.00221.x

Graham-Kevan, N. \& Archer, J. (2008) Does controlling behavior predict physical aggression and violence to partners. Journal of Family Violence, 23, 539-548. doi:10.1007/s10896-008-9162-y

Graham-Kevan, N. \& Archer, J. (2009) Control tactics and partner violence in heterosexual relationships. Evolution and Human Behavior, 30, 445-452. doi:10.1016/j.evolhumbehav.2009.06.007

Hamilton, M. (1959). The assessment of anxiety states by rating. British Journal of Medical Psychology, 32, 50-55. doi: 10.1111/j.2044-8341.1959.tb00467.x

Herrenkohl, T. I., McMorris, B. J., Catalano, R. F., Abbott, R. D., Hemphill, S. A. \& Toumbourou, J. W. (2007). Risk factors for violence and relational aggression in adolescence. Journal of Interpersonal Violence, 22, 386-405. doi:

$10.1177 / 0886260506296986$

Hilbe, J. M. (2007). Negative binomial regression. New York: Cambridge University Press.

Huss, M. T. \& Langhinrichsen-Rohling, J. (2000). Identification of the psychopathic batterer: The clinical, legal and policy implications. Aggression and Violent Behavior, 5, 403422. doi: 10.1016/S1359-1789(98)00038-X

Hutchinson, M. K., \& Holtman, M. C. (2005). Analysis of count data using Poisson regression. Research in Nursing and Health, 28, 408-418. doi:10.1002/nur.20093 
RISK AND PROTECTIVE FACTORS OF AGGRESSION

Jolliffe, D \& Farrington, D. P. (2004). Empathy and offending: a systematic review and metaanalysis. Aggression and Violent Behavior, 9, 441-476. doi:

10.1016/j.avb.2003.03.001

Karpman, B. (1941). On the need for separating psychopathy into two distinct clinical types: Symptomatic and idiopathic. Journal of Criminology and Psychopathology, 3, 112137.

Kashani, J, H., Deuser, W., \& Reid, J. C. (1991). Aggression and anxiety: A new look at an old notion. Journal of the American Academy of Child and Adolescent Psychiatry. 30, 218-223. doi: 10.1097/00004583-199103000-00009

Kaukiainen, A., Björkqvist, K., Lagerspetz, K., Österman, K., Salmivalli, C., Rothberg, S.,..Ahlbom, A. (1999). The relationships between social intelligence, empathy and three types of aggression. Aggressive Behavior, 25, 81-89. doi: 10.1002/(SICI)10982337(1999)25:2<81::AID-AB1>3.0.CO;2-M

Kessler, R.C., McGonagle, K.A., Zhao, S., Nelson, C.B., Hughes, M., Eshleman, \& S....Kendler, K.S. (1994). Lifetime and 12-month prevalence of DSM-III-R psychiatric disorders in the United States. Archives of General Psychiatry, 51, 8-19.

doi:10.1001/archpsyc.1994.03950010008002

Levenson, M. R., Kiehl, K. A. \& Fitzpatrick, C. M. (1995). Assessing psychopathic attributes in a noninstitutionalized population. Journal of Personality and Social Psychology, 68, 151-158. doi: 10.1037/0022-3514.68.1.151

Lewinsohn, P. M., Gotlib, I. H., Lewinsohn, M., Seeley, J. R., \& Allen, N. B (1998). Gender differences in anxiety disorders and anxiety symptoms in adolescents. Journal of Abnormal Psychology, 107, 109-117. doi: 10.1037/0021-843X.107.1.109 
RISK AND PROTECTIVE FACTORS OF AGGRESSION

Lorber, M. F. (2004). Psychophysiology of Aggression, Psychopathy, and Conduct Problems: A Meta-Analysis. Psychological Bulletin, 130, 531-552. doi:10.1037/00332909.130.4.531

Meloy, J. R. (1997). The psychology of wickedness: Psychopathy and Sadism. Psychiatric Annals, 27, 630-633. doi:10.3928/0048-5713-19970901-10

Meyer, T. J., Miller, M. L., Metzger, R. L. \& Borkovec, T. D. (1990). Validation of the Penn State Worry Questionnaire. Behavior Research and Therapy, 28, 487-495. doi: 10.1016/0005-7967(90)90135-6

Miettunen, J., Veijola, J., Lauronen, E., Kantojärvi, L., \& Joukamaa, M. (2007). Sex differences in Cloninger's temperament dimensions - a meta-analysis. Comprehensive Psychiatry, 48, 161-169. doi:10.1016/j.comppsych.2006.10.007

Miller, P. A., \& Eisenberg, N. (1988). The relation of empathy to aggressive and externalizing/antisocial behavior. Psychological Bulletin, 103, 324-344. doi:10.1037/0033-2909.103.3.324

Moffitt, T. E., Caspi, A., Rutter, M., \& Silva, P. A. (2001). Sex differences in antisocial behavior. Cambridge: Cambridge University Press.

O’Donnell, D. A., Schwab-Stone, M. E. \& Ruchkin, V. (2006). The mediating role of alienation in the development of maladjustment in youths exposed to community violence. Development and Psychopathology, 18, 215-232. doi: $10.1017 / \mathrm{S} 0954579406060123$

Pence, E. \& Paymar, M. (1993). Education groups for men who batter: The Duluth Model. New York, US: Springer Publishing

Pico-Alfonso, M. A., Garcia-Linares, M. I., Celda-Navarro, N., Blasco-Ros, C., Echburúa, E. \& Martinez, M. (2006). The impact of physical, psychological, and sexual intimate male partner violence on women's mental health: depressive symptoms, posttraumatic 
RISK AND PROTECTIVE FACTORS OF AGGRESSION

stress disorder, state anxiety and suicide. Journal of Women's Health, 15, 599-611. doi: 10.1089/jwh.2006.15.599

Piliavin, I., Gartner, R., Thornton, C. \& Matsueda, R. L. (1986). Deterrence and rational choice. American Sociological Review, 51, 101-119. doi: 10.2307/2095480

Preacher, K. J. (2002, May). Calculation for the test of the difference between two independent correlation coefficients [Computer software]. Available from http://quantpsy.org.

Reidy, D. E., Zeichner, A. \& Martinez, M. A. (2008). Effects of psychopathy traits on unprovoked aggression. Aggressive Behavior, 34, 319-328. doi: 10.1002/ab.20238

Reiss, S., Peterson, R. A., Girsky, D. M. \& MsNally, R. J. (1986). Anxiety sensitivity, anxiety frequency and the prediction of fearfulness. Behavior Research and Therapy, 24, 1-8. doi: 10.1016/0005-7967(86)90143-9

Rutter, A. \& Hine, D. W. (2005). Sex differences in workplace aggression: An investigation of moderation and mediation effects. Aggressive Behavior, 31, 254-270. doi: $10.1002 / a b .20051$

Stanford, M. S., Houston, R. J., Villemarette-Pitman, N. R. \& Greve, K. W. (2003). Premeditated aggression: clinical assessment and cognitive psychophysiology. Personality and Individual Differences, 34, 773-781. doi: 10.1016/S01918869(02)00070-3

Straus, M. A. (1979). Measuring intrafamily conflict and violence: The Conflicts Tactics (CT) scales. Journal of Marriage and the Family, 41, 75-88. doi:10.2307/351733

Straus, M. A. (2011). Gender symmetry and mutuality in perpetration of clinical-level partner violence: Empirical evidence and implications for prevention and treatment. Aggression and Violent Behavior, 16, 279-288. doi:10.1016/j.avb.2011.04.010 
RISK AND PROTECTIVE FACTORS OF AGGRESSION

Taft, C. T., O’Farrell, T. J., Torres, S. E., Panuzio, J., Monson, C. M., Murphy, M.,...Murphy, C. M. (2006). Examining the correlates of psychological aggression among a community sample of couples. Journal of Family Psychology, 20, 581-588. doi: $10.1037 / 0893-3200.20 .4 .581$

Tangney, J. P., Baumeister, R. F., \& Boone, A. L. (2004). High self-control predicts good adjustment, less pathology, better grades and interpersonal success. Journal of Personality, 72, 271-322. doi: 10.1111/j.0022-3506.2004.00263.x

Tedeschi, J.T. \& Felson, R.B. (1994). Violence, aggression, and coercive actions. Washington, DC: American Psychological Association

Thanzami, V.L., \& Archer, J. (2013). Beliefs about aggression in an Indian sample. Psychological Studies, 58, 133-143. doi: 10.1007/S12646-013-0188-8

Thornton, A. J. V., Graham-Kevan, N. \& Archer, J. (2010). Adaptive and maladaptive traits as predictors of violent and non violent offending behavior in men and women. Aggressive Behavior, 36, 177-186. doi:1 0.1002/ab.20340

Vachon, D. D., Lynam, D. R., \& Johnson, J. A. (2014). The (non)relation between empathy and aggression: Surprising results from a meta-analysis. Psychological Bulletin, 140, 751-773. doi:10.1037/a0035236

Vohs, K. D., Finkenauer, C. \& Baumeister, R. F. (2011). The sum of friends' and lovers' selfcontrol scores predicts relationship quality. Social Psychological and Personality Science, 2, 138-145. doi: 10.1177/1948550610385710 
RISK AND PROTECTIVE FACTORS OF AGGRESSION

Table 1:

Sample Characteristics of the three studies

\begin{tabular}{llll}
\hline & $\begin{array}{l}\text { Study 1 } \\
(N=345)\end{array}$ & $\begin{array}{l}\text { Study 2 } \\
(N=395)\end{array}$ & $\begin{array}{l}\text { Study 3 } \\
(N=364)\end{array}$ \\
\hline Sex & $63 \%$ women & $62 \%$ women & $66 \%$ women \\
Age & $18-58^{\mathrm{a}}$ & $\begin{array}{l}18-63^{\mathrm{b}} \\
M=24.04\end{array}$ & $\begin{array}{l}16-71^{\mathrm{c}} \\
M=22.28\end{array}$ \\
& $M=24.30$ & $S D=8.37$ & $S D=7.25$ \\
Ethnicity & $S D=7.97$ & $93.4 \%$ White & $89.1 \%$ White \\
& $91.0 \%$ White & $3.0 \%$ Asian & $6.4 \%$ Asian \\
& $3.8 \%$ Asian & $0.8 \%$ Black & $1.8 \%$ Black \\
& $1.7 \%$ Black & $2.8 \%$ Other & $2.8 \%$ Mixed \\
Relationship & $3.5 \%$ Other & $62.4 \%$ current partner & $63.3 \%$ current partner \\
Status & $65.6 \%$ current partner & $84.2 \%$ long term & $87.5 \%$ long term \\
\hline
\end{tabular}

${ }^{\mathrm{a}}$ The men were significantly older $(M=27.05)$ than the women $(M=22.72): t(209.78)=4.68, p<.001$ (fractional df reported as Levene's test was significant for all three $t$-tests reported here)

$\mathrm{b}$ the men were significantly older $(M=27.07)$ than the women $(M=22.20): t(181.93)=4.92, p<.001$

${ }^{\mathrm{c}}$ The men were significantly older $(M=25.78)$ than the women $(M=20.60): t(125.83)=4.98, p<.001$

* Long term $=6$ or more months in duration 
RISK AND PROTECTIVE FACTORS OF AGGRESSION

Table 2:

Zero-order correlations between IPV, SSA, Costs, Benefits (for IPV and same-sex) and

EXPAGG scores [men/women] and descriptive for Study 1. (N=345)

\begin{tabular}{|c|c|c|c|c|c|c|c|c|}
\hline & SS perp & IPV Costs & IPV Benefits & SS Costs & SS Benefits & Instrumental & Expressive & Descriptives $^{\mathrm{b} c}$ \\
\hline \multirow[t]{2}{*}{ IPV perp } & $.295^{* * a} \mathrm{a}$ & $-.214 * *$ & $.204 * *$ &.- .049 & $.155^{* *}$ & .105 & .021 & $1.06 / 1.42$ \\
\hline & {$[.218 * / .432 * *]$} & {$[-.199 * /-.222 * *]$} & {$[.193 * / .208 * *]$} & {$[-.058 /-.051]$} & {$\left[.106 / .213^{* *}\right]$} & {$\left[.063 / .155^{*}\right]$} & {$[-.031 / .054]$} & {$[4.16 / 3.48]$} \\
\hline \multirow[t]{2}{*}{ SS perp } & & -.049 & $.255^{* *}$ & -.095 & $.256^{* *}$ & $.303 * *$ & .055 & $1.78 / .49^{*}$ \\
\hline & & {$[-.088 /-.124]$} & {$[.310 * * / .261 * *]$} & {$[-.043 /-.134 *]$} & {$[.260 * * / .228 * *]$} & {$[.345 * * / .234 * *]$} & {$[.113 / .013]$} & [5.37/2.89] \\
\hline \multirow[t]{2}{*}{ IPV Costs } & & & $-.123^{*}$ & $513 * *$ & -.026 & -.009 & .105 & $42.99 / 37.23 * *$ \\
\hline & & & {$[-.173 /-.061]$} & {$\left[.651 * * / .555^{* *}\right]$} & [-.096/-.077] & {$[-.172 /-.007]$} & {$[.105 / .150 *]$} & [7.33/8.18] \\
\hline \multirow[t]{2}{*}{ IPV Benefits } & & & & -.070 & $.571 * *$ & $.399 * *$ & $.130^{*}$ & $16.49 / 17.86$ \\
\hline & & & & {$[-.061 /-.095]$} & {$[.546 * * / .634 * *]$} & {$[.404 * * / .435 * *]$} & [.190*/.087] & {$[6.94 / 7.21]$} \\
\hline \multirow[t]{2}{*}{ SS Costs } & & & & & $-.191 * * \mathrm{a}$ & $-.125^{*}$ & $.129 *$ & $39.33 / 41.41 *$ \\
\hline & & & & & {$[-.284 * * / .093]$} & {$[-.182 * * /-.054]$} & {$[.110 / .132]$} & [9.78/8.54] \\
\hline \multirow[t]{2}{*}{ SS Benefits } & & & & & & $.610 * *$ & $.238 * *$ & $23.14 / 20.11^{* *}$ \\
\hline & & & & & & {$[.568 * * / .626 * *]$} & {$[.288 * * / .225 * *]$} & {$[10.43 / 8.61]$} \\
\hline \multirow[t]{2}{*}{ Instrumental } & & & & & & & $.427 * *$ & $20.24 / 17.97 * *$ \\
\hline & & & & & & & {$[.405 * * / .473 * *]$} & {$[7.22 / 6.28]$} \\
\hline \multirow[t]{2}{*}{ Expressive } & & & & & & & & $25.25 / 25.95$ \\
\hline & & & & & & & & {$[5.64 / 5.23]$} \\
\hline
\end{tabular}

\footnotetext{
${ }^{\mathrm{a}}$ denotes that the correlation coefficients for men and women were significantly different $(Z=-2.13$ for SS/IPV perp; $Z=-3.41$ for SS Costs/Benefits))

$\mathrm{b}$ denotes male/female mean and [standard deviation]

c denotes $d$ values of $-.08 ; .32 ; .72 ;-.11 ;-.24 ; .49 ; .47 ;-.09$ respectively. Positive $d$ value indicates a higher male score

$*$ denotes $p<.05 ; * *=p<.001$;

NB: IPV (intimate partner violence); SSA (same-sex aggression to non-intimates); EXPAGG (measure used to examine expressive and instrumental beliefs); SS (same-sex version of measures)
} 
Table 3:

Negative Binomial Regression of cost, benefits and EXPAGG scores onto IPV and SSA perpetration for Study 1

\begin{tabular}{|c|c|c|c|c|c|c|}
\hline & \multicolumn{3}{|c|}{ IPV } & \multicolumn{3}{|c|}{ SSA } \\
\hline & $\beta$ & SE & $\chi^{2}$ & $\beta$ & SE & $\chi^{2}$ \\
\hline Intercept & .13 & 1.25 & .01 & -.62 & 1.44 & .18 \\
\hline Sex & 3.66 & 2.57 & 2.03 & -2.82 & 2.34 & 1.44 \\
\hline $\operatorname{Costs}^{\mathrm{a}}$ & -.08 & .03 & $10.82 *$ & -.07 & .02 & $9.51^{*}$ \\
\hline Benefits & .05 & .03 & 2.49 & .03 & .03 & .92 \\
\hline Instrumental & -.01 & .04 & .07 & .12 & .04 & $7.32^{*}$ \\
\hline Expressive $^{\mathrm{b}}$ & .09 & .04 & $4.19 *$ & -.01 & .05 & .02 \\
\hline Sex $*$ Costs & .01 & .04 & .03 & .02 & .04 & .30 \\
\hline Sex*Benefits & -.02 & .05 & .18 & .05 & .04 & 1.42 \\
\hline Sex*Instrumental & .05 & .06 & .80 & -.01 & .06 & .01 \\
\hline Sex*Expressive & -.18 & .08 & $4.76^{*}$ & .05 & .09 & .31 \\
\hline
\end{tabular}

${ }^{\mathrm{a}}=$ costs were specific to each aggression type; $*=\mathrm{p}<.05$

Note: The goodness of fit statistic was demonstrated to be at an acceptable level for IPV $($ deviance $=.61)$ and for SSA (deviance $=.47$ ). IPV (intimate partner violence); SSA (same-sex aggression to non-intimates).

${ }^{\mathrm{b}}=$ analysis of this by men and women separately indicated that expressive was only a significant predictor for women. 
RISK AND PROTECTIVE FACTORS OF AGGRESSION

Table 4:

Zero-order correlations between IPV, SSA, Empathy, Anxiety and Self-Control [men/women] for Study $2(N=395)$

\begin{tabular}{|c|c|c|c|c|c|}
\hline & SS perp & Anxiety & Empathy & Self Control & Descriptives \\
\hline \multirow[t]{2}{*}{ IPV perp } & $.475 * * a$ & $.132 * *$ & .081 & $-.187 * *$ & $.78 / 1.60$ \\
\hline & {$[.632 * * / .411 *]$} & {$[.123 / .090]$} & {$[.005 / .074]$} & {$[-.218 * * /-.166 * *]$} & [3.29/3.66] \\
\hline \multirow[t]{2}{*}{ SS perp } & & .084 & -.036 & $-.259 * * \mathrm{a}$ & $2.02 / .93^{*}$ \\
\hline & & {$[.229 * * / .050]$} & {$[-.024 / .027]$} & {$[-.404 * * /-.137 *]$} & {$[5.28 / 3.88]$} \\
\hline \multirow[t]{2}{*}{ Anxiety } & & & $.431 * *$ & $-.348 * *$ & $15.32 / 20.30 * *$ \\
\hline & & & {$\left[.345^{* *} / .381 * *\right]$} & {$[-.413 * * /-.306 * *]$} & [7.21/7.50] \\
\hline \multirow[t]{2}{*}{ Empathy } & & & & -.068 & $57.93 / 65.82 * *$ \\
\hline & & & & {$[-.065 /-.032]$} & {$[11.32 / 10.78]$} \\
\hline \multirow[t]{2}{*}{ Self control } & & & & & $122.22 / 109.59$ \\
\hline & & & & & [21.03/17.19] \\
\hline
\end{tabular}

\footnotetext{
${ }^{a}$ denotes that the correlation coefficients for men and women were significantly different $(Z=2.94$ for SS/IPV perp; $Z=-2.77$ for SS Perp/Self control)

$\mathrm{b}_{\text {denotes male/female mean and [standard deviation] }}$

${ }^{\mathrm{c}}$ denotes $d$ values of $-.17 ; .31 ;-.58 ;-.69 ; .02$ respectively. Positive $d$ value indicates a higher male score

$*$ denotes $p<.05 ; * *=p<.001$;

NB: IPV (intimate partner violence); SSA (same-sex aggression to non-intimates);
} 
Table 5:

Negative binomial Regression of IPV and SSA onto self-control, empathy, and anxiety (Study

2)

\begin{tabular}{lllllll}
\hline & \multicolumn{3}{c}{ IPV } & \multicolumn{3}{c}{ SSA } \\
\hline & $\beta$ & SE & $\chi^{2}$ & $\beta$ & SE & $\chi^{2}$ \\
\hline Intercept & 1.71 & 1.68 & 1.03 & 4.80 & 3.03 & 2.50 \\
Sex & 3.74 & 3.20 & 1.36 & 2.51 & 4.28 & .34 \\
Empathy & .02 & .02 & 1.07 & -.02 & .03 & .54 \\
Self-Control & -.02 & .01 & $5.48^{*}$ & -.04 & .02 & $5.82^{*}$ \\
Anxiety & .01 & .02 & .04 & .05 & .06 & .54 \\
Sex*empathy & -.03 & .04 & .77 & -.02 & .05 & .15 \\
Sex*self-control & -.03 & .02 & 2.09 & -.01 & .03 & .03 \\
Sex*anxiety & .02 & .04 & .13 & -.02 & .09 & .05 \\
\hline
\end{tabular}

Note: Both analyses revealed a goodness of fit statistics that was at an acceptable level for IPV (deviance $=.61)$ and for SSA (deviance $=.42$ ). IPV (intimate partner violence); SSA (same-sex aggression to non-intimates). This analysis was also performed with cognitive/emotional empathy separately and the results were the same. 
Table 6:

Study 3: Zero-order correlations between IPV, SSA, and Psychopathic Traits. [men/women] $(N=364)$

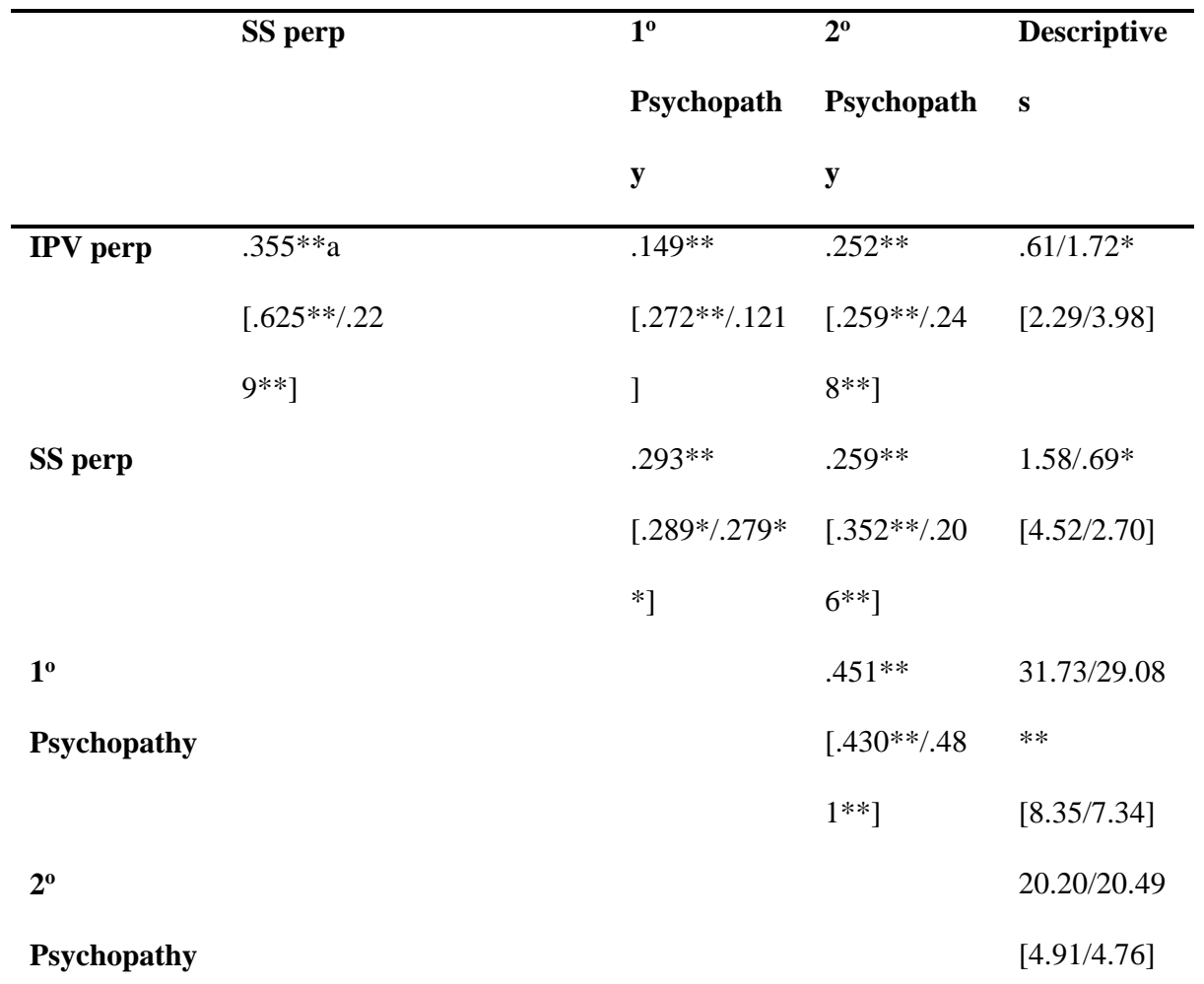

\footnotetext{
${ }^{a}$ denotes that the correlation coefficients for men and women were significantly different $(\mathrm{Z}=4.47$ for IPV/SS Perp)

${ }^{\mathrm{b}}$ denotes male/female mean and [standard deviation]

c denotes $d$ values of $-.27 ; .34 ; .51 ;-.04$ respectively. Positive $d$ value indicates a higher male score

$*$ denotes $p<.05 ; * *=p<.001$;

NB: IPV (intimate partner violence); SSA (same-sex aggression to non-intimates); $1^{\circ}$ psychopathy (primary psychopathy scale); $2^{\circ}$ psychopathy (secondary psychopathy scale)
} 
RISK AND PROTECTIVE FACTORS OF AGGRESSION

Table 7

Study 3: Negative Binomial Regression of psychopathy scores on to IPV and SSA

perpetration

\begin{tabular}{|c|c|c|c|c|c|c|}
\hline & \multicolumn{3}{|c|}{ IPV } & \multicolumn{3}{|c|}{ SSA } \\
\hline & $\beta$ & $\mathrm{SE}$ & $\chi^{2}$ & $\beta$ & $\mathrm{SE}$ & $\chi^{2}$ \\
\hline Intercept & -2.25 & .78 & $8.34 *$ & -10.07 & 1.63 & $38.29 * *$ \\
\hline Sex & -4.96 & 1.63 & $9.24 *$ & 3.66 & 2.23 & 2.69 \\
\hline Primary & -.01 & .03 & .10 & .15 & .03 & $19.48 * *$ \\
\hline Secondary & .14 & .04 & $10.97 *$ & .20 & .06 & $12.60 * *$ \\
\hline Sex* primary ${ }^{\mathrm{a}}$ & .10 & .04 & $5.04 *$ & -.06 & .06 & .10 \\
\hline Sex*secondary & .02 & .08 & .05 & -.03 & .09 & .11 \\
\hline
\end{tabular}


Appendix 1: Dispositional Anxiety Measure (DAM; Bates, 2012)

\section{Your Feelings}

Below is a list of possible situations which may cause you to feel anxious or fearful. Please rate on the following scale how much the statements describe you:

$0=$ doesn't describe me at all to $4=$ describes me perfectly

1. I worry about getting into confrontations with other people.

2. I feel secure and adequate as a person

3. I am scared of losing control

4. I am generally a calm person and don't worry much

5. I am scared of angry people

6. Sometimes my worries overwhelm me

7. I often worry about silly, insignificant things

8. I often feel nervous

9. I'm frightened of feeling angry

10. I find it easy to stop worrying 